\title{
Erratum to: Sacrococcygeal extraspinal ependymoma
}

\author{
Nisar A Wani • Farooq Mir • Abdul Qayum • \\ Parvez Nazir
}

Published online: 23 April 2010

(C) Springer-Verlag 2010

\section{Erratum to: Acta Neurochir}

\section{DOI 10.1007/s00701-009-0503-2}

There was an error in the author's name of the article.

The correct name is:

Nisar A Wani

ahmad77chinar@hotmail.com

The online version of the original article can be found at http://dx.doi. org/10.1007/s00701-009-0503-2.

N. A. Wani $\cdot$ F. Mir $\cdot$ P. Nazir

Department of Radiodiagnosis and Imaging,

Sher-I-Kashmir Institute of Medical Sciences,

Srinagar, Jammu and Kashmir, India

\section{A. Qayum}

Department of Neurosurgery,

Sher-I-Kashmir Institute of Medical Sciences,

Srinagar, Jammu and Kashmir, India

\section{N. A. Wani $(\square)$}

Department of Radiology, SKIMS,

Srinagar 190001, India

e-mail: ahmad77chinar@hotmail.com 